International Journal of Public Finance
E-ISSN: $2548-0499 \quad$ DOI: $10.30927 /$ ijpf.327876
Vol./Cilt: 2 | Issue/Sayı: 1 | (2017), pp. $81-92$
journal homepage: http://dergipark.gov.tr/ijpf

\title{
Devletin Hacmini Belirleyen Faktörler: Ampirik Bir Analiz
}

\author{
Determinants of Government Size: An Empirical Analysis
}

\author{
Nazlı KEYiFLi ${ }^{1} \quad$ Sacit Hadi AKDEDE ${ }^{2}$
}

\section{ARTICLE INFO}

Received: 11.07.2017

Received in revised

form: 06.09.2017

Accepted: 10.09.2017

Available online:

15.09.2017

\section{JEL classification:}

$\mathrm{H} 50, \mathrm{P} 16, \mathrm{C} 23$

\section{Keywords:}

Government Size,

Political Polarization, Panel Data

\begin{abstract}
A B S T R A C T
The purpose of the study is to identify various political, economic and demographic factors that will set out the differences in the size of government across countries. In this study, the effect of political, economic and demographic factors on government size will be analyzed by using panel data analysis method by using 1990-2015 data of the 81 countries included in the World Bank Database. In order to measure the size of government, namely, the dependent variable is government final consumption expenditure as a share of the gross domestic product. Our main findings are as follows. Between political polarization, income inequality, population density, per capita gross domestic product growth, the countries' federal structure and the size of government have a meaningful and negative relationship while democracy, fractionalization, religious fractionalization and the size of government have a significant and positive relationship.
\end{abstract}

\section{MAKALE BiLGISi}

Alındı: 11.07.2017

Gözden geçirilmiş

alındı: 06.09.2017

Kabul: 10.09.2017

Yayın: 15.09.2017

\section{JEL Kodu:}

H50, P16, C23

\section{Anahtar Kelimeler: \\ Kamu Büyüklüğü, \\ Politik Kutuplaşma, \\ Panel Veri}

\begin{abstract}
Ö ZE T
$\mathrm{Bu}$ çalışmanın amacı ülkeler arasındaki devletin boyutundaki faklılıkları ortaya koyacak çeşitli politik, ekonomik ve demografik faktörleri belirlemektir. Çalışmada, Dünya Bankası'nın veri tabanında bulunan 81 ülkenin 1990-2015 dönemi yıllık verileri kullanılarak söz konusu değişkenler ile devletin ekonomik hacmi arasındaki ilişki panel veri analiz yöntemi ile test edilmiştir. Devletin boyutunu ölçmede devletin nihai tüketim harcamalarının gayri safi yurt içi hasılaya oranı ölçüm birimi olarak kullanılmıştır. Başlıca bulgularımız şunlardır. Politik kutuplaşma (political polarization), gelir eşitsizliği, nüfus yoğunluğu, kişibaşı gayri safi yurtiçi hasıla büyümesi, ülkenin federal bir yapıda olması ile devletin boyutu arasında anlamlı ve negatif bir ilişki, demokrasi, siyasi ayrışma (fractionalization) ve dini ayrışma (religious fractionalization) ile devletin boyutu arasında ise anlamlı ve pozitif bir ilişki vardır.
\end{abstract}

\footnotetext{
${ }^{1}$ Araş. Gör., Gümüşhane Üniversitesi, iïBF Maliye Bölümü, n.keyifli@hotmail.com

2 Prof. Dr., Adnan Menderes Üniversitesi, Nazilli iïBF Maliye Bölümü shakdede@adu.edu.tr
} 


\section{Giriş}

Devletin ekonomik hacminin sınırının ne olması gerektiği ve nasıl belirleneceğine yönelik tartışmalar kamu maliyesi yazınındaki önemli konular arasında yer almaktadır. Son yüzyılda sanayileşmiş ülkelerin çoğunda devletin mutlak ve göreli büyüklüğü bu konunun önemini daha da arttırmıştır. Bununla birlikte, sosyo-ekonomik yapı, gelişmişlik düzeyi, hükümet programları ve düzenlemeler gibi faktörler ülkeler arasında tamamen aynı olmadığından devletin boyutunda da ülkeler arasında büyük farklııklar bulunmaktadır. Bu nedenle, tüm ülkelerde geçerli olabilecek bir kamu sektörü hacmi belirlemek zordur. Dolayısıyla, devletin boyutunda bu gibi farklılıkların neden mevcut olduğu ve bu farklılıkları hangi faktörlerin şekillendirdiği önemlidir (Pevcin, 2004; 41-42, Gramc, 2007; 130). Bu bağlamda, geleneksel literatür nüfus yoğunluğu (Alesina, Baqir ve Easterly, 1999), gelir dağılımı (Meltzer ve Richard, 1981), coğrafi yapı (Lindqvist ve Östling 2010), büyüme hızı (Mukherjee, 2003) ve dış ticaret (Rodrik,1998) gibi ekonomik ve demografik faktörleri devletin boyutu üzerindeki etkisini açıklamakta kullanmaktadır. Ancak, geleneksel literatürün yanı sıra hükümete özgü politik belirleyicilerin de devletin boyutunu belirlemede önemli roller üstlendiği görülmektedir (Dash ve Raja, 2012; 5). Bununla birlikte, ülkelerin farklı koşulları göz önüne alındığında söz konusu hacmi ölçmede kullanılan doğrudan bir ölçüm birimi olmadığı farklı göstergelerden yararlanıldığı görülmektedir (Akbulut, 2015; 44). Ancak, devletin boyutunun ölçülmesinde yaygın olarak harcama yanlı göstergelerden yararlanılmakta; bu çerçevede daha çok kamu harcamalarının GSYiH' ya oranının veya devletin tüketim harcamalarının GSYiH' ya oranının kullanıldığı görülmektedir. Kamu harcamaları; genel devlet tüketim harcamaları, sübvansiyonlar ve transferler, sosyal yardımlar gibi kalemlerden oluşmaktadır. Devlet, bir ekonomide kamu politikası yürütmek için harcama ve vergileri mali araçlar olarak kullanmaktadır (Posner,1971; 25). Böylelikle, kamu harcama oranı ile kamu kaynaklarının kullanımının kapsamı yani devletin faaliyetleri ortaya konulmaktadır (Pevcin, 2004; 42).

Çalışma, giriş ve sonuç bölümleri dahil dört bölümden oluşmaktadır. Çalışmanın birinci bölümünde ekonomik, demografik ve politik faktörlerin devletin hacmi üzerindeki etkisine ilişkin ampirik literatüre yer verilmiş, akabinde ikinci bölüm ise ampirik uygulamaya ayrılmıştır. Söz konusu bölümde çalışmada kullanılan model ve veri seti tanımlanırken daha sonra elde edilen ampirik bulgular yer almaktadır. Sonuç ve ampirik bulguların değerlendirilmesi ile çalışma son bulmaktadır.

\section{Devletin Hacmine ilişkin Ampirik Literatür}

Kamu maliyesi yazınında devletin boyutunu belirleyen faktörler üzerinde belirli dönemlerde ve belirli ülke gruplarına yönelik çalışmalar yapılmıştır. Yapılan literatür incelemesi sonucunda ekonomik faktörlerin devletin boyutu üzerindeki etkisini araştıran birçok çalışmaya rastlanmış olup ekonomik, demografik ve özellikle siyasi faktörlerin devletin boyutu üzerindeki etkisini ele alan az sayıda uluslararası çalışma olduğu, ulusal düzeyde ise bir çalışma olmadığı görülmüştür. Özellikle konuyla ilgili 
ulusal literatürdeki boşluğu doldurmak amacıyla ekonomik, demografik ve politik faktörlerin devletin boyutu üzerindeki etkisi ampirik olarak incelenmiştir. Çalışmamızla ilgili literatürde yer alan çalışmalara bakıldığında;

Blais, Blake ve Dion (1993), 1960-1987 yılları arasında 15 liberal demokrasiyi kapsayan çalışmalarında partilerin (sol-sağ) devletin hacmi üzerindeki etkisini belirlemeye çalışmışladır. Analiz sonucunda, sol partilerin sağ partilerden biraz daha fazla harcama yaptıkları sonucuna ulaşılmıştır.

Husted ve Kenny (1997), çalışmalarında 1950-1998 dönemi için 46 ülkenin yıllık verilerini kullanarak gelir dağılımı ve hükümet büyüklüğü üzerinde seçmenin etkisi panel veri analiz yöntemiyle araştırılmıştır. Sonuç olarak, oy kullanma önündeki engellerin (baş vergisi, okur-yazarlık) kaldırıması gelir dağılımı talebini arttırmış ve fakir vatandaşlara yönelik refah ve sosyal yardım harcamalarının arttırılması hükümetin büyümesinde önemli bir neden olduğu görülmüştür.

Annett (2000), çalışmasında 1960'lar, 1970 'ler ve 1980 'lerin on yıllık ortalamalarını kullanarak ülkenin nüfusunun etnik ve dini ayrışması ile siyasi istikrarsızlık ve devlet harcamaları arasındaki ilişki panel veri yöntemiyle analiz edilmiştir. Örneklem boyutu 108 ülke ile sınırlandırılmıştır. Sonuç olarak, ayrışmanın (etnik ve dini) yüksek olduğu ülkelerde daha yüksek seviyede devlet harcamaları yapıldığı sonucuna ulaşılmıştır.

Mukherjee (2003), çalışmasında iki ülke grubu ele alınmış olup 1978-1996 dönemi için OECD ülkeleri ve 1980-1996 dönemi için OECD’ ye üye olmayan ülkelerde temsil edilen siyasi parti sayısındaki artışın ve çoğunluğa sahip partinin büyüklüğünün devlet hacmi üzerindeki etkisi panel veri analiz yöntemi kullanılarak test edilmiştir. Analiz sonucunda, temsil edilen parti sayısı arttıkça hükümetin daha fazla sübvansiyon ve transfer harcaması yaptığı sonucuna ulaşılmıştır.

Plumper ve Martin (2003), çalışmalarında 83 ülkenin 1975-1997 dönemi için demokrasi ile ekonomik performans arasındaki ilişki panel veri yöntemiyle analiz edilmiştir. Sonuç olarak, demokrasi düzeyi arttıkça devlet harcamalarının kalitesinin arttığı ve devletin ekonomideki payının da değiştiği sonucuna ulaşılmıştır. Ayrıca, yine aynı çalışmada demokrasi seviyesi yükseldikçe hükümetlerin GSYiH'nın büyük bir bölümünü harcama eğiliminde olduğu görülmüştür.

Ricciuti (2004), çalışmasında 1975-1995 yılları arasında 19 OECD ülkesinde siyasi ayrışmanın maliye politikası üzerindeki etkisi panel veri yöntemi kullanarak analiz edilmiştir. Analiz sonucunda, siyasi ayrışmanın fazla olmasının daha çok devlet harcamasına neden olacağı sonucuna ulaşılmıştır. Ayrıca, siyasi ayrışmanın daha az olduğu bir siyasi yapıda hükümetin hesap verilebilirliği ve şeffaflığı artmaktadır.

Bawn ve Rosenblut (2006), çalışmalarında 17 Batı Avrupa ülkesinin 1970-1998 dönemine ait verilerini kullanarak parlamenter sistemlerde siyasi partilerin büyüklüğü ve sayısının politika sonuçları üzerindeki etkisi panel veri yöntemiyle test edilmiştir. Sonuç olarak, mecliste çok partili koalisyonların artması kamu sektörünün boyutunun artmasına neden olduğu sonucuna ulaşılmıştır. 
Gramc (2007), tarafından yapılan bir başka çalışmada 35 gelişmiş demokratik ülkenin 1980-2002 dönemi için devlet hacmindeki değişimleri etkileyen ekonomik, sosyal, politik, demografik ve kültürel faktörler panel veri yöntemiyle analiz edilmiştir. Analiz sonucunda, devletin tüketim boyutundaki farklılıkların açıklanmasında ekonomik faktörlerin daha önemli olduğu ancak transfer harcamalarının boyutundaki değişimi açıklarken ise politik, sosyal ve kültürel faktörlerin daha önemli olduğu sonucuna ulaşılmıştır.

Linqvist ve Östling (2010), çalışmalarında 74 ülkenin 1995-2005 dönemine ait verileri kullanarak politik kutuplaşma ve devletin hacmi arasındaki ilişki ampirik olarak analiz edilmiştir. Analiz sonucuna göre, politik kutuplaşma ve devletin hacmi arasındaki ilişkinin demokratik ve devlet hacminin küçük olduğu ülkelerde daha güçlü olduğu ancak antidemokratik ülkelerde ise bu ilişkinin olmadığı sonucuna ulaşıımıştır.

Dash ve Raja (2012), 14 Hint eyaletinin 1980-2007 dönemine ait yıllık verilerini kullanarak hükümetin politik özelliklerinin kamu harcamalarının dağılımında etkili olup olmadığı panel veri yöntemiyle analiz etmişlerdir. Sonuç olarak, politik belirleyicilerin kamu harcamalarının dağılımında etkili olduğu ve koalisyon hükümetlerinin kamu harcamalarını daha da arttırdığı sonucuna ulaşılmıştır.

Afonso ve Jalles (2016), çalışmalarında 1970-2010 dönemi için 140 ülke verisini kullanarak devlet hacmi, kurumlar ve ekonomik faaliyetler arasındaki ilişki dinamik panel veri analiz yöntemi ile incelenmiştir. Analiz sonucunda, devlet hacminin büyük olmasının, ekonomik faaliyetleri olumsuz etkilediği; devlet hacminin küçük olmasının ise kurum kalitesini ve GSYiH'yı olumlu etkilediği sonucuna ulaşılmıştır.

Yukarıda değinilen çalışmaların bulgularından da anlaşıldığı üzere farklı ekonomik, demografik ve özellikle politik faktörlerin devlet hacmini belirlemede etkili olduğunu görülmektedir. Devletlerin farklı sosyo-ekonomik yapılara sahip olması ülkeler arasında simetrik bir devlet boyutuna ulaşılamadığını da göstermektedir. Bu bağlamda, devlet hacminin küçük olmasının hükümetin hesap verilebilirliği ve şeffaflığını arttırdığı ancak söz konusu boyutun büyük olması durumunda ise ekonomik faaliyetlerin olumsuz etkilediği ortaya çıkmaktadır. Öte yandan, politik kutuplaşma, dini farklılıklar ve siyasi farklılıklar gibi politik değişkenlerin de devletin boyutunu etkileyici faktörler olduğu görülmektedir.

\section{Devletin Hacmini Belirlemeye ilişkin Faktörler: Ampirik Bulgular}

Bu bölümde Dünya Bankası veri tabanında bulunan 81 ülkeye ilişkin, 1990-2015 dönemini içeren, ekonomik, demografik ve özellikle politik faktörlerin devletin hacmi üzerindeki etkisi ampirik olarak incelenmiştir. Verilerin analizinde panel veri yönteminden yararlanılmıştır. Zaman serisi ve yatay kesitin bir arada kullanımına imkan sağlayan panel veri yöntemi, hem dönemlere hem de birimlere ilişkin daha fazla bilgi kullanımı sağlamaktadır (Tatoğlu, 2013:3). 


\subsection{Yöntem}

Panel veri tekniği bireyler, firmalar, ülkeler, hane halkı gibi birimlere ait yatay kesit gözlemlerini belli bir dönemde bir araya getirilmesine imkan sağlayan bir ekonometrik tekniktir (Hsiao, 2007: 6). Panel veri modellerinde, hem yatay kesit (N) hem de zaman ( $T$ ) boyutlarının bir arada kullanılmasına imkan sağlamaktadır. Bu durumda gözlem sayısının artmasına ve serbestlik derecesine sahip olma, birim ve zaman etkilerinin gözlenmesine imkan tanıma gibi avantajlara sahiptir (Woolridge, 2002: 452, Tatoğlu, 2013: 3). Bu bağlamda, panel veri tekniği güvenilir ve daha etkin tahminlere imkan sağlaması nedeniyle ampirik literatürde yoğun bir şekilde kullanılmaktadır (Hsiao, 2007: 2).

Panel veri tekniğinin kullanıldığı modellerde genel itibariyle sabit etkiler ve rassal etkiler model tahmincileri kullanılmaktadır. Modelde zamana ve birimlere özgü etkiler sabit kabul edildiğinde sabit etkiler tahmincisi, zamana özgü ve birimlere özgü etkiler modele hata teriminin bileşeni olarak kabul edilidiğinde rassal etkiler tahmincisi ile analiz gerçekleştirilir. Hausman (1978) testi sonuçlarına göre panel veri modelinde hangi tahmincinin kullanılacağına karar verilir. Söz konusu testte $\mathrm{H}_{0}=0$ hipotezi rassal etkiler modelinin geçerli olduğunu $\mathrm{H}_{0} \neq 0$ ise sabit etkiler modelinin geçerli olduğu kabul edilmektedir.

Çalışmada, Annet (2000), Gramc (2007) ve Mukherjee (2003) gibi yazarların çalışmalarında kullandıkları ekonometrik modeller referans alınarak aşağıdaki tahmin denklemi oluşturulmuştur.

$P P S_{i t}=\beta_{0}+\beta_{1} P P_{i t}+\beta_{2} G I N_{i t}+\beta_{3} P D_{i t}+\beta_{4} G D P_{i t}+\beta_{5} D I N_{i t}+\beta_{6} D E C_{i t}+\beta_{7} F R C_{i t}+\beta_{8} F E D_{i t}+u_{t}$

Çalışmada devletin hacmini belirlemeye yönelik faktörler panel veri ekonometrik yöntemi ile araştırılmıştır. Çalışmanın zaman kısıtlarını 1990-2015 yılları arasındaki dönem oluşturmaktadır. Yukarıdaki denklemde PPS devletin nihai tüketim harcamalarının Gayri Safi Yurtiçi Hasıla' ya (GSYiH) oranını, PP Politik kutuplaşmayı (political polarization), GIN gelir eşitsizliğini, PD nüfus yoğunluğunu, GDP kişi başı GSYiH büyümesini, DIN dini ayrışma (religious fractionalization) düzeyini, DEC demokrasi düzeyini, FRC siyasi ayrışma (fractionalization) düzeyini temsil etmektedir. Ülkenin federal bir yapıda olup olmadığı (FED), kukla değişken olarak modele dahil edilmiştir.

\subsection{Veri Seti}

Çalışmada ekonomik, demografik ve politik faktörlerin devlet hacmi üzerindeki etkisinin ampirik olarak araştırılması hedeflenmektedir. Tablo 1' de çalışmada kullanılan değişken seti ve kaynağı sunulmuştur. 
Tablo 1: Değişken Seti ve Kaynağı

\begin{tabular}{|c|c|c|}
\hline Değişken Türü & Değişken Adı & Kaynak/Açıklama \\
\hline Bağımlı Değişken & $\begin{array}{l}\text { Devletin nihani tüketim } \\
\text { harcamaları (\% GSYiH) }\end{array}$ & \multirow{4}{*}{ The World Bank } \\
\hline \multirow{7}{*}{ Bağımsız Değişken } & Gini & \\
\hline & Nüfus yoğunluğu & \\
\hline & Kişi başı GSYïH büyümesi & \\
\hline & $\begin{array}{l}\text { Politik kutuplaşma (political } \\
\text { polarization) }\end{array}$ & $\begin{array}{l}\text { :"government responsibility"anket } \\
\text { sorusunun standart sapmasılyla } \\
\text { hesaplanır. (World Values Survey) }\end{array}$ \\
\hline & $\begin{array}{l}\text { Dini Ayrışma (religious } \\
\text { fractionalization) }\end{array}$ & $\begin{array}{l}\text { : "0 ile 1" arasında değer alır. } 0= \\
\text { sosyal çeşitlilik yok, } 1=\text { sosyal } \\
\text { çeşitlilik yüksek. (The Quality of } \\
\text { Governmet Dataset) }\end{array}$ \\
\hline & Demokrasi & $\begin{array}{l}\text { : "0 ile } 10 " \text { arasında değer alır. } 0= \\
\text { antidemokrasi, } 10=\text { pür demokrasi. } \\
\text { (Marshall and Jaegger's Polity's } 4 \\
\text { Dataset) }\end{array}$ \\
\hline & Siyasi ayrışma (fractionalization) & $\begin{array}{l}\text { : "0 ile 1" arasında değer alır. } 0= \\
\text { tek parti, } 1=\text { koalisyon. (The World } \\
\text { Bank's Dataset on Political } \\
\text { Institutions) }\end{array}$ \\
\hline Kukla Değişken & Federal yapı & $\begin{array}{l}\text { :"federal yapı var" anlamına gelen } \\
\text { ülkeler için } 1 \text { diğer ülkeler için } 0 \\
\text { olarak tanımlanmaktadır. }\end{array}$ \\
\hline
\end{tabular}

Not: Nüfus yoğunluğu değişkeni kilometre kareye düşen insan sayısı ve kişibaşı GSYiH büyümesi değişkeni kişibaşı GSYiH'nın yıllık büyüme oranı olarak alınmıştır

\subsection{Tanımlayıcı İstatistikler, Tahmin Sonuçları ve Bulgular}

Önsel bir bilgi edinmek için öncelikle tanımlayıcı istatistiklere bakılmıştır. Modelde yer alan değişkenlere ilişkin tanımlayıcı istatistikler Tablo 2'de verilmiştir. Analiz döneminde (1990-2015), ülkelerin devletin nihai tüketim harcamaları ortalama \% 16 düzeyindedir. Ülkelerin politik kutuplaşma değerinin ortalaması 2,81 düzeyinde gerçekleşmiştir. Politik kutuplaşmanın en yüksek olduğu ülke 3,70 seviyesiyle El Salvador iken politik kutuplaşmanın en düşük olduğu ülke ise 1,91 seviyesi ile Pakistan'dır. Öte yandan, ilgili dönemde nihai tüketim harcaması açısından en düşük tüketim harcaması \%2,80 oranıyla Zambiya iken \% 48,06 ile Kuveyt en yüksek tüketim harcaması yapan ülke konumundadır. Nüfus yoğunluğu açısından en yüksek yoğunluğa sahip ülke kilometre kareye düşen insan sayısı bakımından 7553,63 kişi ile Singapur iken en düşük yoğunluğa sahip ülke ise 2.27 kişi ile Avustralya olmuştur. Dini ayrışmanın en düşük olduğu ilk üç ülke Fas $(0,003)$, Türkiye $(0,004)$ ve Cezayir $(0,009)$ iken en yüksek dini ayrışmaya sahip ilk üç ülke ise Güney Afrika $(0,86)$, Avustralya $(0,82)$ 
ve Amerika Birleşik Devletleri (0,82)'dir. Demokrasisi en düşük (0) Azerbaycan, Bahreyn, Belarus, Kazakistan, Kuveyt, Libya, Ruanda gibi ülkeler iken demokrasisi en yüksek (10) ülkeler Avustralya, Kanada, Şili, Kıbrıs, Çek Cumhuriyeti, Finlandiya, Almanya, Macaristan, İtalya, Japonya, Litvanya, Hollanda, Yeni Zelanda, Norveç, Polonya, Slovakya, Slovenya, İspanya, İsveç, İsviçre, Trinidad ve Tobago, İngiltere, Uruguay, Amerika Birleşik Devletleri'dir.

Tablo 2: Tanımlayıcı İstatistikler

\begin{tabular}{lccccc}
\hline Değişken Adı & Gözlem & Ortalama & Std. Hata & Minimum & Maksimum \\
\hline Devletin Nihai Tüketim & 391 & 15.82 & 5.21 & 2.80 & 48.06 \\
Harcaması & & & & & \\
Politik Kutuplaşma & 146 & 2.81 & 0.36 & 1.91 & 3.70 \\
Gini & 288 & 38.70 & 9.34 & 19.49 & 63.9 \\
Nüfus Yoğunluğu & 405 & 204.14 & 698.64 & 2.27 & 7553.63 \\
Kişibaşına GSYì & 396 & 2.16 & 4.53 & -30.26 & 35.44 \\
Dini Ayrışma & 405 & 0.44 & 0.23 & 0.00 & 0.86 \\
Demokrasi & 396 & 6.34 & 3.62 & 0 & 10 \\
Siyasi Ayrışma & 397 & 0.61 & 0.22 & 0 & 0.99 \\
Federal & 405 & 0.17 & 0.37 & 0 & 1 \\
\hline
\end{tabular}

Tahmin modelinde öncelikle birim ve/veya zaman etkilerinin olup olmadığına karar verilmiştir. Birim ve zaman etkisinin varlığı LR testi ile sınanmıştır. LR Testi sonuçları Tablo 3'de sunulmuştur.

Tablo 3: Birim ve Zaman Etkisinin Birlikte Sınanması: LR Testi Sonuçları

\begin{tabular}{|l|l|}
\hline Birim Etkisi & Prob (0.000) \\
\hline Zaman Etkisi & Prob (1.000) \\
\hline
\end{tabular}

LR testi sonucuna göre $\% 95$ güven düzeyinde, birim etkinin ( $\mathrm{HO}=0$ ) olduğunu söyleyen hipotez reddedilmiştir. Testin sonucuna göre \%95 güven düzeyinde, zaman etkinin $(\mathrm{HO}=0)$ olduğunu söyleyen hipotez reddedilememiştir. Yapılan testler sonucunda modelde birim etkinin olduğu zaman etkisinin olmadığı sonucuna ulaşılmıştır. Dolayısıyla, modelde birim etki vardır ve Klasik Modelin uygun olmadığı sonucuna ulaşılmıştır. Birim etkinin varlığı $F$ testi ve $L M$ testi ile de ayrı ayrı sınanmıştır. Tablo 4'de F testi ve LM testi sonuçları sunulmuştur. 
Tablo 4: Birim Etkinin Sınanması

\begin{tabular}{|l|c|c|}
\hline Test Őzeti & Test Istatistiği & Olasılık Değeri \\
\hline F Testi & 11.12 & 0.000 \\
\hline LM Testi & 25.54 & 0.000 \\
\hline
\end{tabular}

Her iki test sonunca göre \%95 güven düzeyinde, birim etkinin $\left(\mathrm{H}_{0}=0\right)$ olduğunu söyleyen hipotez reddedilmiştir. Sonuç olarak, kurulacak modelde birim etkinin olduğu sonucuna ulaşılmıştır. Çalışmaya ilişkin veri setindeki ülkelerin Dünya Bankası veri tabanından rastgele seçilmesinden dolayı modelin tesadüfi olduğu varsayılmaktadır. Ancak, birim ve/veya zaman etkilerinin varlığının tespitinden sonra bu etkilerin sabit mi yoksa tesadüfi mi olduğunu belirlemek için Hausman Testi de ek olarak kullanılmıştır. Tablo 5'de Hausman Test sonuçları sunulmaktadır.

Tablo 5: Hausman Test Sonuçları

\begin{tabular}{|l|c|c|}
\hline Test Özeti & Istatistik & Olasılık \\
\hline Rassal Yatay Kesit & 10.97 & 0.0892 \\
\hline
\end{tabular}

Hausman testi sonucunda olasılık değerinin \%5'den büyük çıkması, kurulacak modelin tesadüfi etkiler modeli olduğunu göstermekte olup varsayımımızı destekler niteliktedir. Ancak, daha etkili sonuçlar elde edebilmek için varsayımlardan sapmaların da test edilmesi gerekmektedir. Yapılan testler sonucunda tesadüfi etkiler modelinde otokorelasyon ve heteroskedasitenin varlığı öngörülmektedir. Dolayısıyla seriler otokorelasyondan ve değişen varyanstan arındırıldıktan sonra nihai modele ulaşılmıştır. Tablo 6'de elde edilen sonuçlar sunulmuştur.

Tablo 6: 1990-2015 Dönemi Dünya Bankası'nın Veri Tabanında Bulunan 81 Ülkenin Panel Veri Sonuçları

\begin{tabular}{|c|c|c|c|c|}
\hline \multicolumn{5}{|c|}{ Bağımlı Değişken: PPSgt } \\
\hline \multirow{2}{*}{$\begin{array}{l}\text { Bağımsız } \\
\text { Değişkenler }\end{array}$} & \multirow[t]{2}{*}{ Katsayı } & Robust & \multirow[t]{2}{*}{ t-İstatistiği } & \multirow[t]{2}{*}{ Olasılık Değer } \\
\hline & & St.Hata & & \\
\hline PP & -2.044 & 0.676 & -3.02 & $0.003^{\star \star \star}$ \\
\hline GIN & -0.119 & 0.050 & -2.35 & $0.019^{* *}$ \\
\hline PD & -0.006 & 0.002 & -2.50 & $0.012^{* *}$ \\
\hline GSMH BÜYÜME & -0.476 & 0.120 & -3.96 & $0.000^{\star * *}$ \\
\hline DIN & 5.061 & 1.874 & 2.70 & $0.007^{\star *}$ \\
\hline DEC & 0.229 & 0.136 & 1.68 & $0.092^{*}$ \\
\hline FRC & 6.918 & 2.467 & 2.80 & $0.005^{\star *}$ \\
\hline
\end{tabular}




\begin{tabular}{|c|c|c|c|c|}
\hline FED & -2.935 & 1.097 & -2.67 & $0.007^{\star \star}$ \\
\hline Gözlem Sayısı & & & 108 & \\
\hline$R^{2}$ & & & 0.5037 & \\
\hline $\begin{array}{l}\text { F-Isstatistiği } \\
\text { (Olasılık) }\end{array}$ & & & $0.000^{* * *}$ & \\
\hline
\end{tabular}

Not: $* * *, * *, *$ sırasıyla $\% 1, \% 5$ ve $\% 10$ anlamlılık düzeylerini göstermektedir.

Tablo 5'deki sonuçlara göre, varsayımlardan sapmaların düzeltildiği nihai modelin istatistiki olarak anlamlı olduğu görülmektedir (F-testi). Modeldeki bağımsız değişkenlerin ve kukla değişkeninin devletin nihai tüketim harcamaları üzerindeki etkisi sınandığında da istatistiki olarak anlamlı sonuçlara ulaşılmıştır. Politik kutuplaşma ve kişi başına GSYiH büyümesi ile devlet tüketim harcamaları arasında \%1 düzeyinde istatistiksel olarak anlamlı ve negatif bir ilişki, gini katsayısı, nüfus yoğunluğu ve ülkenin federal bir yapıda olması ile devlet tüketim harcamaları arasında $\% 5$ anlamlılık düzeyinde negatif ilişki tespit edilmiştir. Dini ayrışma ve siyasi ayrışma ile devlet tüketim harcamaları arasında pozitif ve \%5 düzeyinde anlamlı bir ilişki bulunmuştur. Demokrasinin devlet tüketim harcamalarını pozitif yönde etkilediği ve \%10 düzeyinde anlamlı olduğu tespit edilmiştir.

\section{Sonuç ve Tartışma}

Çalışmada Dünya Bankası'nın veri tabanında bulunan 81 ülkenin 1990-2015 dönemine ait yıllık verilerinin 5'er yıllık ortalamaları alınarak politik, ekonomik ve demografik faktörler ile devletin ekonomik hacmi arasındaki ilişki panel veri analiz yöntemi ile araştırılmıştır. Veri setini 5'er yıllık oluşturulmasının nedeni model için önem arz eden politik kutuplaşma verisinin 5' er yıllık düzenleniyor olmasıdır. Devletin ekonomik hacmini belirlemede devletin nihai tüketim harcamalarının GSYiH' ya oranı ölçüm birimi olarak kullanılmıştır. Öte yandan, son zamanlarda devletin boyutunu belirlemede ekonomik ve demografik faktörlerin yanı sıra politik faktörlerin de etkili olduğu görülmüştür. Bu doğrultuda, politik kutuplaşma, dini farklılıklar ve siyasi farklılıklar gibi politik değişkenlerin devlet hacmini etkileyici faktörler olarak dikkate alınması gerektiği kanısına ulaşılmıştır.

Ampirik analiz sonuçlarımız, politik kutuplaşma ile devletin nihai tüketim harcamaları arasında güçlü bir negatif ilişki olduğunu göstermektedir. Yani, politik kutuplaşma devlet hacminin küçülmesine neden olmaktadır. Gelir dağııımın bozulması devletin nihai tüketim harcamalarını azaltıcı bir etki göstermektedir. Bunun nedeni, düşük gelirlilerin kamu harcamasının arttırılmasına yönelik taleplerinin devlet katında karşııı bulmaması durumu olabilir. Ayrıca, ülkelerin demokrasi seviyeleri arttıkça devletin ekonomideki payı da değişmektedir. Devletin tüketim harcamaları ile demokrasi arasında anlamlı ve pozitif bir ilişki söz konusudur. Demokrasi seviyesi arttıkça devletler daha fazla harcama eğiliminde olmaktadır. Farklı siyasi partilerin de devletin boyutunun şekillenmesinde önemli bir rolü vardır. Hükümetteki siyasi partilerin sayısının fazla olması daha yüksek devlet tüketimine neden olmaktadır. Öte 
yandan, nüfus yoğunluğu, kişi başına GSYiH büyümesi gibi demografik ve ekonomik değişkenler ile devletin tüketim harcamaları arasında anlamlı ve negatif bir ilişki olduğu görülmektedir. Sosyal çeşitliliğin de (dini farklılık) devletin boyutu üzerinde etkili olduğu görülmektedir. Sosyal çeşitliliğin yüksek olması daha yüksek devlet tüketimine neden olmaktadır. Yani, devlet tüketim harcamalarını kullanarak toplumdaki hoşnutsuzluğu gidermeyi amaçlar. Son olarak, bir ülkenin federal bir yapıya sahip olması devlet hacminin küçülmesine yol açar. Genel itibariyle ampirik analiz sonucunda elde edilen bulgular, literatür ile paralellik göstermektedir. Devlet hacmindeki farklılıkları açıklamada politik, ekonomik ve demografik faktörlerin etkili olduğu görülmüştür. 


\section{Kaynakça}

Afonso, A. \& Jalles, J.T. (2016). "Economic performance, government size, and institutional quality", Empirica, 43(1), pp.83-109.

Akbulut, H. (2015). "Kamu Sektörünün Hacmi: Trükiye-Avrupa Birliği Karşılaştırması”, Amme Idaresi Dergisi, 48 (3), ss.41-59.

Alesina, A., Baqir, R. \& Easterly, W. (1999). "Public Goods and Ethnic Divisions", Quarterly Journal of Economics, 114 (4), pp.1243-1284.

Annet, A. (2000). "Social Fractionalization, Political Instability, and the Size of Government", Washington:IMF.

Bawn, K. \& Rosenbluth, F. (2006). "Short versus long coalitions: electoral accountability and the size of the public sector", American Journal of Political Science, 50(2), pp.251-265.

Blais, A., Blake, D. \& Dion, S. (1993). "Do parties make a difference? Parties and the size of government in liberal democracies", American Journal of Political Science, 37 (1), pp.40-62.

Dash, B., B. \& Raja, A., V. (2012). "Political Determinants of the Allocation of Public Expenditures: A Study of the Indian States", National Institute of Public Finance and Policy, Working Paper No.2012-101, pp. 4-27.

Gramc, B. (2007). "Factor of the size of government in developed countries", Prague Economic Papers, 16 (2), pp.130-142.

Hausman, J., A. (1978). "Specification Tests in Econometrics", Econometrica, No: 46 (2), pp. 1251-1271.

Hsiao, C. (2007). "Panel Data Analysis-Advantages and Challenges”, 16 (1), pp.1-22.

Husted, T., A. \&Kenny, L.,W. (1997). "The Effecr of the Expansion of the Voting Franchise on the Size of Government", Journal of Political Economy, 105 (1), pp.54-82.

Lindqvist, E. \& Östling, R. (2010). "Political Polarization and the Size of Government", The American Political Science Review, Vol. 104 (3), pp. 543-565.

Melzer, A., H. \& Richard, S., F. (1981). "A Rational Theory of the Size of Government", Journal of Political Economy, 89 (5), pp.914-927.

Mukherjee, B. (2003). "Political Parties and the Size of Governmet in Multiparty Legislatures Examining Cross-Country and Panel Data Evidence", Comparative Political Studies, Vol. 36 (6), pp. 699-728.

Pevcin, P. (2004). "Cross-Country Differences in Governmet Sector Activities", Zb.Rad.Sveuc.u Rij.,Ekon,fak.,god., Vol. 22 (2), pp. 41-59. 
Pluemper, T. \& Martin, C., W. (2003). "Democracy, Government Spending, and Economic Growth: A Political-Economic Explanation of the Barro-effect", Public Choice, 117 (1-2), pp.27-50.

Posner, R. A. (1971). "Taxation by Regulation", The Bell Journal of Economics and Management Science, 2(1), pp.22-50.

Ricciuti, R. (2004). "Political fracmentation and fiscal outcomes", Public Choice, 118 (3), pp.365-388.

Rodrik, D. (1998). “Why Do More Open Economies Have Bigger Government?”, Journal of Political Economy, 106 (5), pp.997-1032.

Tatoğlu, Y., F. (2013). Panel Veri Ekonometrisi: Stata Uygulamalı, 2. Baskı, İstanbul: Beta Yayınları.

Wooldridge, M., J. (2002). Econometric Analysis of Cross Section and Panel Data, Cambridge: The MIT Press. 